\title{
Fertility after Induced Abortion: a Register- Based Study in Finland in 2000-2008
}

\author{
HEINI VÄISÄNEN, M.Soc.Sc, Ph.D. Student, University of Helsinki, Finland \\ MARKUS JOKELA, Ph.D., University Researcher, University of Helsinki, \\ Finland
}

\section{Abstract}

The article explores the determinants offertility behaviour after an induced abortion in Finland. The purpose of the study is to determine whether there are socio-demographic factors associated with the risk of having repeat abortions. The data were collected from the Registry of Induced Abortions and from the Medical Birth Registry in 2000-2008. The study population consists of the 63,763 women who had their first induced abortion during that time. Our results indicate that there are significant differences in fertility patterns of women with different socio-demographic backgrounds. The likelihood of repeat abortion was high for teenagers, parous, low socio-economic status (SES), urban and unmarried women. Delivery was the most likely for 20-34-year-olds, rural and childless women, and for women, who were living with their partner and were no longer students. New pregnancy was unlikely for at least 30-year-olds, parous and high SES groups. The results show that these socio-demographic patterns should be taken into account when developing post-abortion counselling.

Keywords: induced abortion, fertility, life time analysis, Finland

\section{Introduction}

Roughly 10,000 induced abortions are performed in Finland every year, which means that about nine induced abortions are performed per 1,000 women of the fertile age annually. One third of women having an abortion have already had at least one previous abortion and the proportion of repeat abortions has increased since the beginning of the decade. (Heino et al. 2009). The aim of the study is to investigate the determinants of different fertility patterns after an induced abortion. For example, Heikinheimo, Gissler and Suhonen (2009) studied the outcomes of the pregnancies after an abortion performed in Helsinki in 2000-2002. The women were followed until the end of the year 2006. Previous abortions, parity and young age were risk factors for repeat abortion, and the age of 25-29 years increased the likelihood of childbirth. Niinimäki et al. (2009) found that also low socio-economic status (SES), being unmarried and cohabiting increased the risk of repeat abortion.

1 The study is based on the master's thesis of Heini Väisänen (2010): Abortin jälkeiseen hedelmällisyyteen vaikuttavat tekijät Suomessa. [Determinants of fertility after abortion in Finland.] Department of Social Research, University of Helsinki. 
As Katherine Trent and Eve Powell-Griner $(1991,1121)$ point out in their article Differences in Race, Marital Status and Education Among Women Obtaining Abortions, there is a lack of social scientific theory in abortion research even though abortion is clearly a very relevant aspect of fertility. One remedy to this situation is to link theoretical frameworks of fertility behaviour to abortion research. Finland is among the very few countries in the world to have reliable and comprehensive abortion registries, making the Finnish registry data on abortions unique. Despite this research opportunity, only few quantitative social scientific studies about the subject have been conducted in Finland.

The aim of the present study was to investigate the determinants of different fertility patterns after an induced abortion. Characterizing post-abortion fertility behaviour helps to determine whether there is a group of women with a greater risk of having repeat abortions than in the population on average. The object was firstly to identify characteristics predicting the outcome of pregnancy following the first induced abortion and to assess whether these predictors interact with parity. Secondly, we examined whether changes in relationship status and SES between the first induced abortion and next pregnancy were related to pregnancy outcome. Thirdly, we also discussed the situation of women who did not conceive after their first induced abortion.

\section{Background}

The theoretical background of the study was based on life course theory and life history theory. These theoretical approaches were linked to the actual fertility and abortion behaviour through the proximate determinants framework of John Bongaarts and Robert G. Potter (1983). Evolutionary, cultural and micro-economic approaches of fertility behaviour also are presented to learn more about the reasons which lead to different outcomes of pregnancies.

In the life course theory, there are five paradigmatic principles that guide research on human lives. Firstly, human development is a lifelong process and all changes in environmental factors or socioeconomic status affect the lives of individuals. Secondly, people are in charge of their own life and they make choices that are possible in given time and place. Thirdly, the life course is shaped by historical events and geographic locations people live in. Fourthly, the consequences of events an individual experiences vary according to their timing in his or her life. Finally, socio-historical influences depend on the network of other people an individual is living with. (Elder et al. 2003, 10-13).

To elaborate life course theory further Michael J. Shanahan, Scott M. Hofer and Lilly Shanahan (2003) have linked the framework with life history theory, which is based on natural selection and evolutionary principles. They have emphasized that human behaviour is caused by interaction of social and biological forces, which define ranges of likely behaviour. According to the writers, life course theorists should bear in mind that behaviour can result from the need to enhance fitness, and that evolutionary 
theory can serve as a framework that integrates diverse findings and thus creates new hypotheses and explanations. (Ibid., 599-600, 603).

The importance of biological factors in fertility studies has also been stressed by Bongaarts and Potter (1983) in their book Fertility, Biology and Behavior. The authors proposed that social, economic and environmental variables affect fertility through proximate determinants which include (in modern societies) sexual activity, couple's fecundity and the length of fertile period, contraception and willingness to have an abortion. In addition, chance plays a role, as not even two alike couples always follow the same fertility patterns. (Ibid., 1-3, 163).

Human fertility behaviour has also been approached from an economic perspective. According to Gary S. Becker (1991), the willingness to invest in children affects the number of children in a family. Nowadays parents invest more on their children than they did in traditional rural societies. The amount invested depends on parents' education, income and consumption preferences (ibid). Along the same lines, Sarah Blaffer Hrdy (1999) has emphasized that from evolutionary point of view it is not in the best interest of mothers to give birth to as many children as possible, but to ensure good living conditions to themselves and their children. Therefore women tend to improve their own life conditions before they have children, if they have the choice. (Ibid). Ron J. Lestaeghe (2010) has explained fertility trends through the framework of second demographic transition, which means that people prefer individual well-being over large families because of the value change that has occurred in Western societies since the 1960s.

Most of the aborted pregnancies have probably been unintended (i.e. unwanted or mistimed). Wildsmith, Guzzo and Hayford (2010) point out that unintended pregnancy does not only mean that the pregnancy was not planned, but that it is not suitable to give birth in the given time and context. Pregnancy desirability is a result of multiple social and economic influences rather than an individual decision only (Santelli et al. 2003, 97). For instance, relationship status, SES, family and religious background, peer influence and availability of social support affect the willingness to give birth, as they are related to the stage of the life course of the women (Wildsmith et al. 2010, 14-15). Hayford and Guzzo (2010) studied the association between age, relationship status and the planning status of births in the United States in order to determine the normative context of childbearing. They found that although the planning status of births was associated with age, the association became weaker when relationship status was controlled and that it was higher for first and second births than higher parity births. This suggests that the variation by age seems to be in association with social norms rather than causal processes related to aging. In the US it seemed that marriage was still preferred context for childbearing in contrast to cohabitation, and that SES did not predict the planning status of births. However, the study only covered pregnancies that were carried to term, excluding all induced (and spontaneous) abortions. In addition, educational or occupational history was not known, so the estimate of SES might not be accurate. (Ibid., 387-9). 
Figure 1 shows how we linked different fertility theories to Potter's and Bongaarts' framework of proximate determinants of fertility. Human agency and individual characteristics refer to the characteristics of the pregnant woman, her spouse (if she has one) and people around her. Education, SES, values and attitudes are important, as people's decisions in a given situation are dependent on these factors. Biological and evolutionary factors mean the willingness to have children, the number of children in the family and the woman's age. The level of urbanisation, living conditions and the apartment an individual has are defined as environment. Culture and society signify social policy, historical period, cultural values and norms. All variables mentioned above affect fertility through the proximate determinants, as defined above. In the case of pregnancy, the woman has to decide, whether she will give birth or have an abortion (has the pregnancy not ended in a spontaneous abortion $)^{2}$. The same variables that affect fertility, affect this decision. Certainly there are many more decisions to take before childbearing - for example decision to be sexually active, to form a relationship and whether or not to use contraception (Hayford \& Guzzo 2010,372) - but as in this study we assumed that pregnancies ending in induced abortions were most likely unintended, the focus is on the decision to carry the pregnancy to term or to have an induced abortion. Only, if the indication for abortion was (risk of) fetal disease, we assumed that the pregnancy was planned, but resulted in induced abortion because of the unfortunate medical reason.

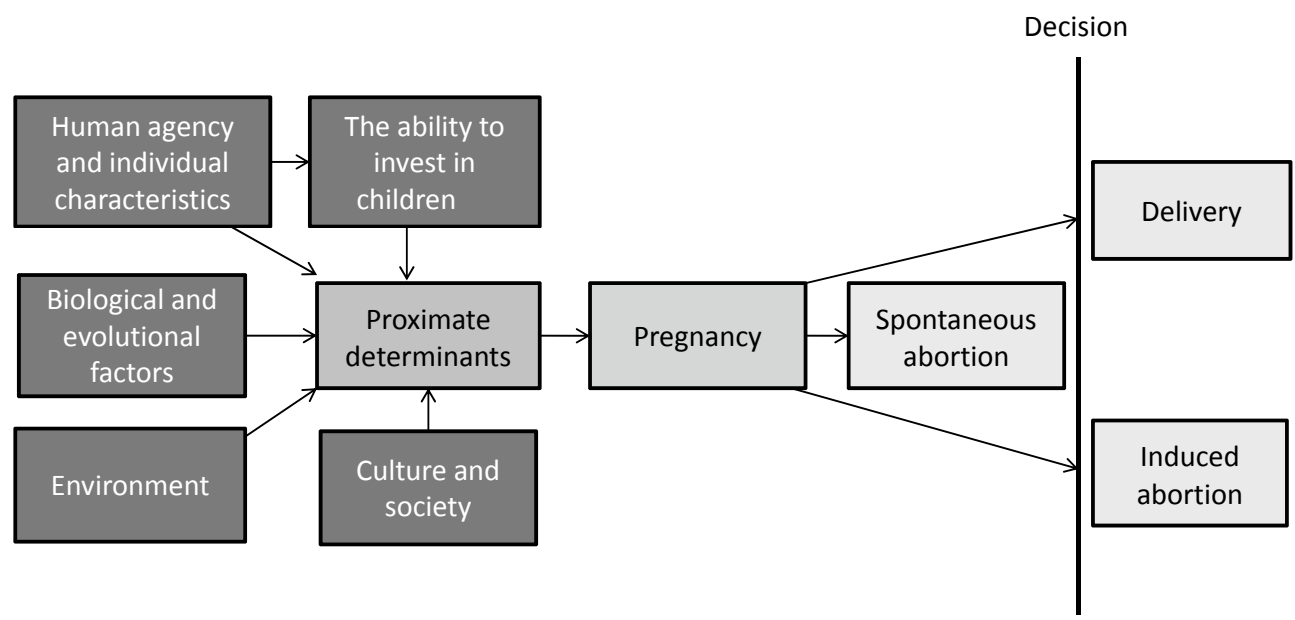

Figure 1. Determinants of fertility behaviour in modern societies (adapted from Bongaarts \& Potter 1983).

2 In Bongaarts' and Potter's (1983) framework abortion is considered to be one of the proximate determinants, because it affects fertility. In this article, however, the focus is on abortions, so the framework of Bongaarts and Potter has been modified so that the proximate determinants are seen as factors that affect immediately before the pregnancy. 


\section{Data and methods}

The data of the study were from the Finnish Registry of Induced Abortions, to which data from each abortion in Finland are collected routinely. In addition, we had data from the Medical Birth Registry, concerning the women who had had abortion(s) during the studied period of time. Both registers are maintained by National Institute for Health and Welfare. The Registry of Induced Abortions includes data from legal terminations of pregnancies up to 24 weeks of gestation and the Medical Birth Registry pregnancies ending at 22 weeks of gestation or more, or resulting in delivery of an infant weighting at least $500 \mathrm{~g}$ (Heikinheimo et al. 2009, 821).

According to a study conducted in 1993, 99 percent of legal induced abortions were included in the Registry of Induced Abortions (Gissler et al. 1996, 378). Although most variables are recorded in good or satisfactory validity levels, the data quality was sometimes poor: social class as well as cohabitation status of single women were reported correctly only in about 80 percent of the cases, and gestation length from 64 to 81 percent (depending on the method used to measure the length) (ibid, 379).

We examined women who had their first induced abortion in the period from 2000 to 2008 and we followed them until their next pregnancy or until the end of the year 2008. There were 63,763 women who had their first induced abortion during the studied period of time. 19,240 of them conceived again. In 7,743 cases the outcome of the new pregnancy was a repeat abortion and in 11,497 cases a delivery. Cases in which the abortion was performed because of one of the parents was unable to take care of the child $(\mathrm{N}=8)$ were not included in the data, because it is extremely rare to have an induced abortion based on this indication ${ }^{3}$ (Heino et al. 2009). Women who had a sterilisation at the same time they had their first abortion were also excluded $(\mathrm{N}=648)$, because they were no longer able to conceive and therefore were not in the focus of this study.

Statistical analyses were conducted using life time analysis (cumulative hazard functions and Cox regression model). The results of analyses are presented as hazard ratios (HR), which signify the ratio of hazard functions and can also be interpreted as percentage differences by computing $100 *(\mathrm{HR}-1)$ (Singer and Willett 2003, 527). Both univariate (controlled for age) and multivariate models were calculated. Separate Cox regression models were fitted for 1) probability of childbirth and 2) probability of induced abor-

3 In Finland abortion is permitted, if at least one of the following is fulfilled: "(1) considerable strain caused by living or other condition (so-called social reason), (2) age $<17$ years, (3) age $>40$ years (4), women has given birth to at least four children (5), medical reasons of the woman (pregnancy is a risk for her life or health, her sickness, physical defect or infirmity or she is not able to take care of the child), (6) medical reason of the father (he is not able to take care of the child), (7) medical reason of the fetus (mental deficiency, severe illness or handicap), and (8) ethical reasons including rape, incest and other reasons mentioned in the penal code" (Knudsen et al. 2003, 260-261). 
tion. When the probability of delivery was estimated, pregnancies ending in a repeat abortion were censored and vice versa. No censoring was conducted in the basis of the age of the women. All Cox regression models were conducted using the same data set and the same independent variables, which enabled us to compare the results (ibid, 592-4). To analyse how changes in SES and relationship status predicted pregnancy outcome, we used logistic regression analysis. The results are presented as odds ratios (OR). All statistical analyses were conducted using Stata-software, version 11.

The estimated timing of conception was used as a dependent variable in Cox regression analyses to avoid possible bias that would have otherwise been caused by different gestation times in pregnancies ending in induced abortion or delivery (as abortion is normally performed at the early stages of pregnancy). In logistic regression analyses the dependent variable was the outcome of the pregnancy ( $0=$ abortion, $1=$ delivery) after the first induced abortion.

All independent variables were measured at the time of the first induced abortion, except for the variables in the logistic regression analyses of the effect of the change in relationship status or SES, where the latter situation is measured at the time of either the second abortion or the delivery. Independent variables were: Age in seven groups, first being 14 or younger and the last 40 or older. Groups in between were divided into five-year age groups. Marital status was categorised into unmarried, married, divorced, widowed and cohabiting. In some of the models a dichotomised relationship status variable was used $(0=$ no partner, $1=$ living with a partner). $S E S$ based on women's occupation at the time of induced abortion was divided into eight groups according to the definition of Statistics Finland (2010): students, self-employed persons, upper-level employees, lower-level employees, manual workers, unemployed persons, housewives and others (others being mainly disability pensioners). In logistic regression analyses of the effect of change in SES, the amount of groups was reduced to three: students, workers (including self-employed persons, manual workers, upper-level and lowerlevel employees) and others (i.e. housewives, unemployed persons and pensioners). Parity (i.e. the number of previous live births) was studied in five different groups: 0,1 child, 2 children, 3 children and 4 or more children or as a dichotomised variable ( $0=$ childless, $1=$ =parous). The indication for induced abortion was determined on the basis of indications defined in the law (see footnote 3). The effect of population density of women's municipal of residence was studied in three groups: rural which is less than 100, suburban which is from 100 to 999 and urban which is at least 1000 inhabitants per square kilometre. The level of urbanisation was calculated on the basis of the population density in woman's home municipality.

All variables used in this study, were based on the variables of the registries of Induced Abortions and Medical Birth Registry. The information of marital status and occupation of women are recorded on the basis of their own report. SES is automatically coded 
on the basis of the information of the occupation. The age of a woman is recorded as it appears her identity document. The home municipality is verified from the Population Register Center of Finland, as is the number of children, if the indication for abortion is already having at least four children. Otherwise the number of children is asked directly from the woman. The indication for abortion is recorded as the doctor has reported it based on the law.

\section{Results}

Table 1 describes the distribution of the next pregnancy outcomes and women not conceiving again after the first induced abortion by socio-demographic characteristics of the women. Altogether 30 percent of the women conceived again after the first induced abortion ${ }^{4}$, with 18 percent ending in a delivery and 12 percent in a repeat abortion. In other words, 60 percent of the second pregnancies ended in a delivery and 40 percent in a repeat abortion. In these women, who had already had one abortion, the proportion of abortions was higher than in the population in general, as normally less than 200 induced abortions are performed per one thousand pregnancies (Heino et al. 2009). Most of the women having abortions were quite young, unmarried, childless and/or students. The most common indication for the first abortion was so-called "social reason". (Table 1).

4 Pregnancies ending in spontaneous abortion were not included, as miscarriages not treated in specialized health care are not recorded in registries. 
Table 1. The proportion of new pregnancy outcomes according to the sociodemographic determinants.

\begin{tabular}{|c|c|c|c|c|}
\hline & & Delivery & $\begin{array}{c}\text { Repeat } \\
\text { abortion }\end{array}$ & $\begin{array}{c}\text { No } \\
\text { pregnancy }\end{array}$ \\
\hline \multirow[t]{8}{*}{ Age } & Less than 15 & 0.7 & 1.2 & 0.9 \\
\hline & $15-19$ & 33.3 & 38.3 & 24.7 \\
\hline & $20-24$ & 29.4 & 31.3 & 25.5 \\
\hline & $25-29$ & 19.4 & 15.0 & 16.1 \\
\hline & $30-34$ & 11.5 & 8.3 & 13.6 \\
\hline & $35-39$ & 4.8 & 4.8 & 12.5 \\
\hline & 40 or more & 0.8 & 1.1 & 6.9 \\
\hline & Total & 100.0 & 100.0 & 100.0 \\
\hline \multirow{6}{*}{$\begin{array}{l}\text { Marital } \\
\text { status }\end{array}$} & Married & 12.5 & 12.5 & 21.5 \\
\hline & Unmarried & 67.1 & 66.8 & 56.5 \\
\hline & Widowed & 0.2 & 0.1 & 0.2 \\
\hline & Divorced & 3.8 & 4.4 & 5.3 \\
\hline & Cohabiting & 16.5 & 16.1 & 16.6 \\
\hline & Total & 100.0 & 100.0 & 100.0 \\
\hline \multirow[t]{9}{*}{ SES } & Student & 48.0 & 50.5 & 40.6 \\
\hline & Self-employed & 1.2 & 0.9 & 1.6 \\
\hline & Upper-level employer & 7.6 & 4.2 & 8.7 \\
\hline & Lower-level employer & 21.6 & 16.2 & 25.1 \\
\hline & Manual worker & 15.0 & 16.6 & 15.8 \\
\hline & Unemployed & 2.7 & 3.2 & 2.2 \\
\hline & House wife & 1.8 & 6.4 & 4.1 \\
\hline & Other & 2.0 & 2.0 & 1.9 \\
\hline & Total & $100.0(9,871)^{* *}$ & $100.0(6,472)$ & $100.0(53,237)$ \\
\hline \multirow[t]{6}{*}{ Parity } & 0 & 80.4 & 62.1 & 57.0 \\
\hline & 1 & 10.1 & 18.9 & 16.0 \\
\hline & 2 & 6.5 & 12.2 & 17.1 \\
\hline & 3 & 2.3 & 5.0 & 7.2 \\
\hline & 4 or more & 0.9 & 1.9 & 2.7 \\
\hline & Total & 100.0 & 100.0 & 100.0 \\
\hline \multirow{9}{*}{$\begin{array}{l}\text { Indica- } \\
\text { tion for } \\
\text { the 1st } \\
\text { abortion }\end{array}$} & Social reason & 82.5 & 86.0 & 85.8 \\
\hline & Less than 17 years old & 10.0 & 11.2 & 6.6 \\
\hline & 40 years or older & 0.3 & 0.5 & 3.4 \\
\hline & Has 4 children & 0.4 & 0.9 & 1.2 \\
\hline & Medical reason of the woman & 0.3 & 0.2 & 0.4 \\
\hline & Risk of medical reason of the fetus* & 2.4 & 0.4 & 0.8 \\
\hline & Medical reason of the fetus ${ }^{*}$ & 4.2 & 0.8 & 1.7 \\
\hline & Ethical reasons & 0.1 & 0.1 & 0.1 \\
\hline & Total & 100.0 & 100.0 & 100.0 \\
\hline \multirow{4}{*}{$\begin{array}{l}\text { Popu- } \\
\text { lation } \\
\text { density }\end{array}$} & 1000 or more & 17.5 & 18.0 & 18.5 \\
\hline & 100-999 & 36.2 & 38.9 & 36.1 \\
\hline & Less than 100 & 46.3 & 43.1 & 45.4 \\
\hline & Total & $100.0(10,644)$ & $100.0(7,257)$ & $100.0(41,761)$ \\
\hline $\mathrm{N}(\mathrm{all})$ & & 11.419 & 7,746 & 44,598 \\
\hline
\end{tabular}

*The risk of medical reason and medical reason of the fetus are presented here separately, because that is how they are recorded to the Registry of Induced Abortions.

**N presented, if it differs from the $\mathrm{N}$ of the row "all". 
Figure 2 presents the cumulative hazard functions for delivery and repeat abortion after the first induced abortion by age groups. The risk of delivery increases throughout the study period, especially for younger women. Most of the childbirths happen several years after the first induced abortion. The risk of repeat abortion, by contrast, decreases towards the end of the studied period of time indicating that the risk of repeat abortion is the highest shortly after the first induced abortion. The younger the women were at the time of the first abortion, the greater was the risk of repeat abortion.

Figure 3 presents the results of the multivariate Cox regression models of the determinants of delivery and repeat abortion (the univariate and multivariate results did not differ substantially; data not shown). The indication for abortion was included as a covariate in the analyses, although the HRs are not presented in the figure. The variable had an effect only on the likelihood of childbirth, but no effect on the likelihood of repeat abortion. Women having had an abortion because of fetal disease or risk of a fetal disease, were five times more likely to give birth than others $(\mathrm{HR}=5.40$, $\mathrm{CI}=4.82-6.04, \mathrm{p}<0.001$ and $\mathrm{HR}=5.31, \mathrm{CI}=4.60-6.13, \mathrm{p}<0.001$, respectively).

Women aged 20-29 years at the time of the first induced abortion were more likely than other age groups to give birth later on. Teenagers had the greatest risk of repeat abortion after which the risk of repeat abortion decreased fairly linearly with age. Women aged 30-34 years still had relatively high probability of delivery, but the risk of repeat abortion was small, while women aged 35 or more had low probability of both pregnancy outcomes.

Divorced women were more likely to give birth than any other marital status group (except for widows, whose confidence interval was, however, wide enough to suggest that the estimate is not exact). Married women were as likely to give birth as cohabiting women, and both groups had higher probability of giving birth than unmarried women. The effect of marital status on the risk of repeat abortion was quite small. Compared to unmarried or cohabiting women, married women were slightly less likely to have a repeat abortion and divorced women were in a somewhat greater risk of doing so. 

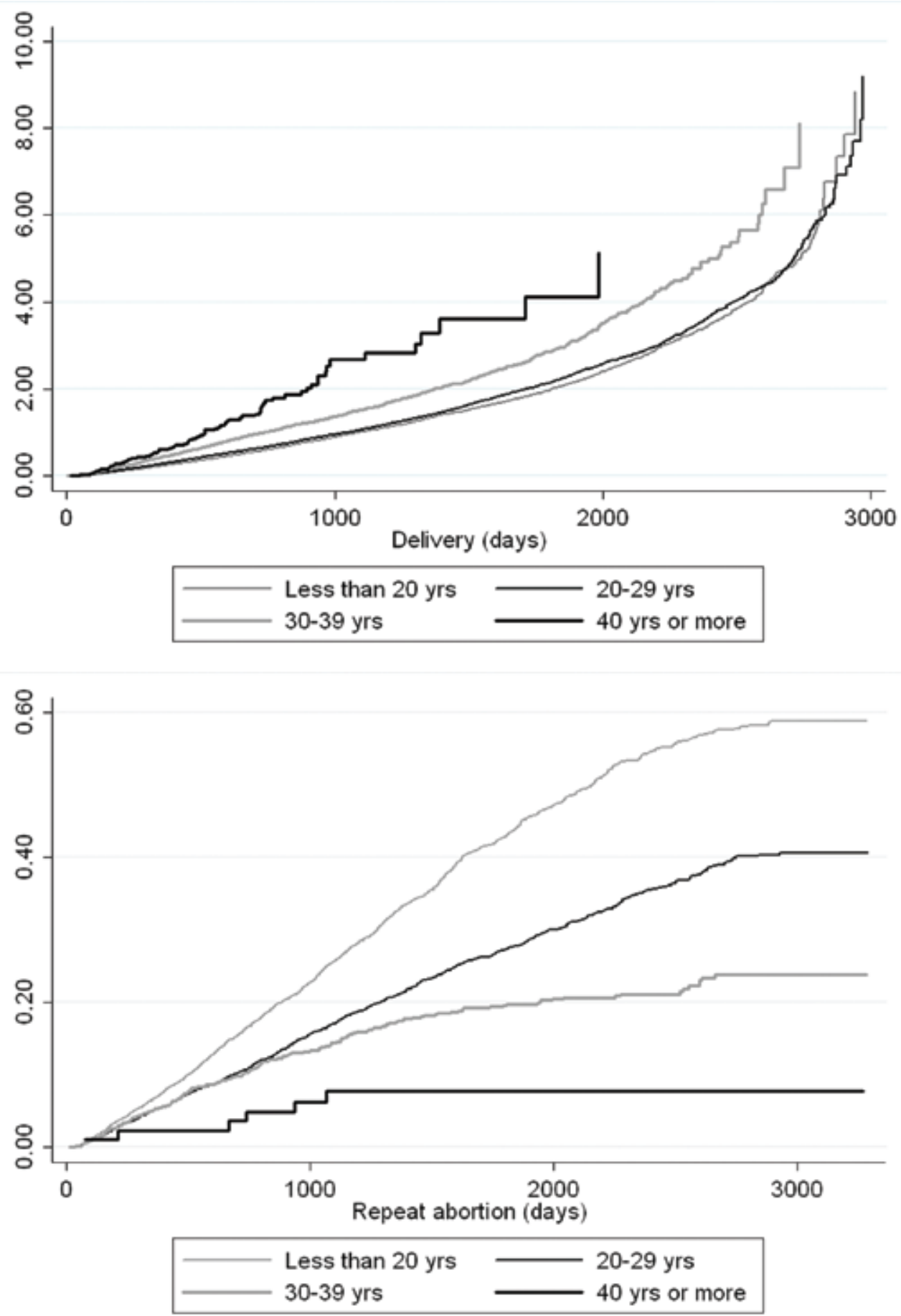

Figure 2. Nelson-Aalen cumulative hazard functions for the risk of (1) childbirth and (2) repeat abortion by age group after the first induced abortion. 


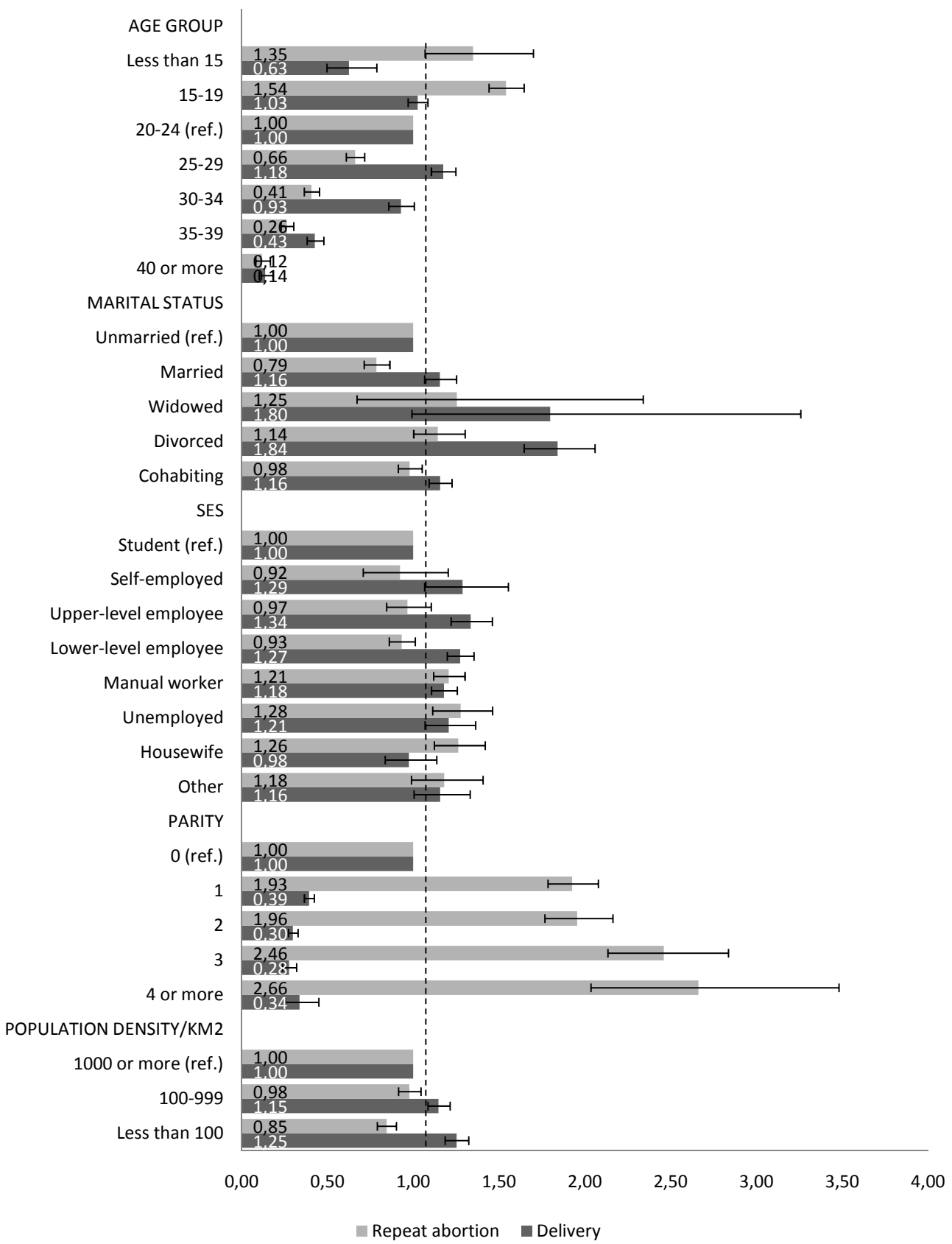

Figure 3. Determinants of pregnancy outcome after the first induced abortion, multivariate Cox regression models, proportional hazards with $95 \%$ Cls. (The effect of the indication for abortion not shown.) 
Univariate (controlled for age) and multivariate logistic regression analysis was then conducted for the women who conceived twice during the study period $(\mathrm{N}=19,240)$, to examine the effect of change in relationship status between the first induced abortion and next pregnancy outcome (the univariate and multivariate results did not differ substantially; data not shown). The univariate model showed that relationship status clearly affected the likelihood of giving birth instead of repeat abortion: compared to those with no relationship at either time, women who had no relationship at the time of first induced abortion were 15 times more likely to give birth in their next pregnancy, if they had found a partner between the first induced abortion and the following pregnancy $(\mathrm{OR}=15.14, \mathrm{CI}=13.90-16.50, \mathrm{p}<0.001)$. Women who were in a relationship at both times, were 6 times more likely to give birth than women with no partner $(\mathrm{OR}=6.47$, $\mathrm{CI}=5.81-7.20, \mathrm{p}<0.001)$. Ending the relationship after the first induced abortion resulted in slightly smaller likelihood of childbirth $(\mathrm{OR}=0.74, \mathrm{CI}=0.64-0.85, \mathrm{p}<0.001)$ than having no relationship at all.

All socioeconomic groups gave birth more likely than students and housewives, although these differences were not large. The effect on the risk of repeat abortion was even smaller than the one on delivery. Unemployed persons, manual workers and housewives aborted from 20 to 30 percent more likely than other groups, but otherwise differences were not statistically significant. When we conducted the logistic regression analysis of the change in SES (divided into three groups: students, workers and others) between the first induced abortion and next pregnancy outcome, the students' lower likelihood of giving birth showed up clearly: compared to women who were students at the time of both pregnancies, those who were no longer student after the first induced abortion and either went to work or stayed at home (i.e. the group "others") had greater likelihood to give birth $(\mathrm{OR}=1.93, \mathrm{CI}=1.71-2.19, \mathrm{p}<0.001$ and $\mathrm{OR}=2.88$, $\mathrm{CI}=2.34-3.53, \mathrm{p}<0.001$ respectively).

Population density had a small but statistically significant effect on childbirth. Women living in rural areas had higher probability of giving birth than urban women. The likelihood to have a repeat abortion was slightly smaller in rural areas than in urban environment. Parity clearly affected the likelihood of giving birth or having repeat abortion. The more children one had, the more likely she was to perform a repeat abortion. Parous women were noticeably less likely to give birth than childless women.

We also studied the interaction of parity with age, SES, marital status and population density. Except for population density, all the predictors had a significant interaction effect with parity when predicting childbearing or repeat abortion (data not shown). The associations between socio-demographic factors and delivery/repeat abortion by parity are reported in the table 2 (Cox regression models calculated separately to childless and parous women). This enables us to show how the HRs differ according to parity. Regardless of the statistically significant interaction term, the interaction effect of parity 
with age was moderate. Childless and parous women had only small differences in the HRs of both pregnancy outcomes within the same age group. Childbirth was the most likely for 25-29-year-olds, had they children or not, and for 30-34-year-olds with no children. Repeat abortion was unlikely for women aged at least 25 regardless of their parity. Other variables, however, resulted in more clearly observable interaction effects. Marital status increased the likelihood of delivery if the woman was either married or cohabiting and had no children or if she had children and was divorced or widowed. Marital status had no effect on the likelihood on repeat abortion for childless women, but parous women were less likely to abort again if they were married or cohabiting. All childless SES groups gave birth more likely than students, but there were almost no effect for parous women. Repeat abortion was slightly more likely for childless manual workers and unemployed women than for other SES groups. Parous women had slightly smaller likelihood of repeat abortion if they were upper- or lower-level employees. 


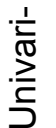

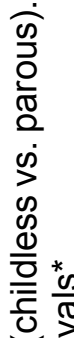

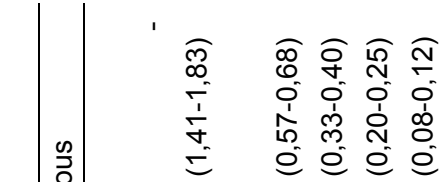

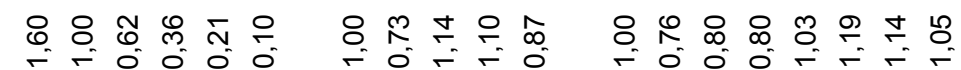
롤.

잉

วิ당

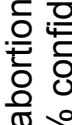

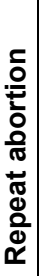

กิ

ำ

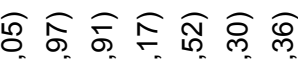

它全

e e e 0

(1)

인

क्ष

응

完

哭

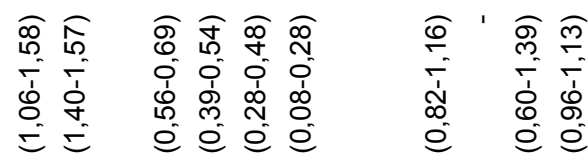

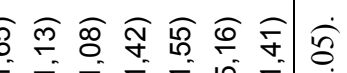

穴

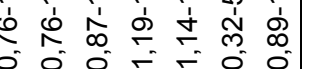

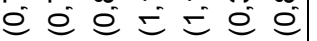

节

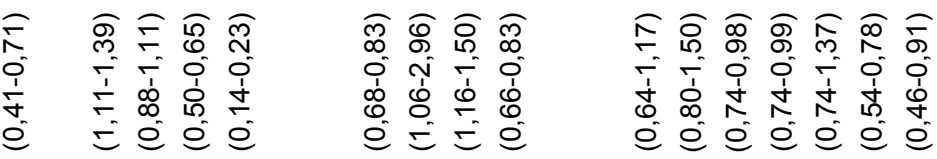

은 은

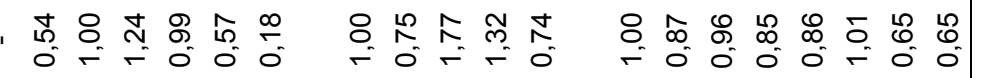

응

응

$\frac{\pi}{\pi} \frac{0}{0}$

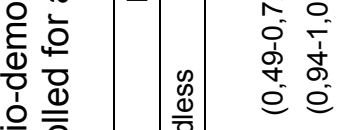

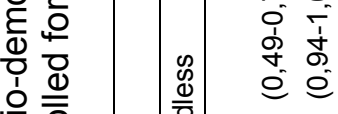

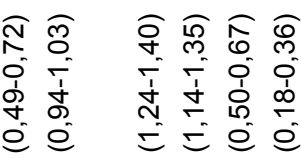

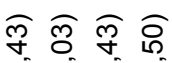

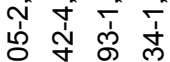

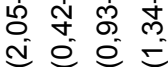

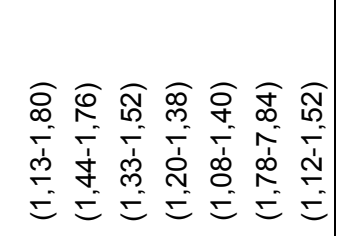

号

员 


\section{Discussion}

As the results show, socio-demographic characteristics predict differences in fertility behaviour after the first induced abortion. Young age, low SES, already having children, living in an urban environment and/or having no spouse increased the risk of repeat abortion. The likelihood of childbirth, in turn, increased if the woman was from 20 to 34 years old, had high SES, had not given birth earlier, lived in a rural area and/or had a spouse. If the reason for the first induced abortion was fetal disease, the likelihood of childbirth multiplied in comparison to other first induced abortion indications. This confirms the assumption that those pregnancies were planned, but pregnancies ending in induced abortion based on other indications were not. New pregnancy was unlikely if the woman was over 30 years old, had high SES or already had children. Many of them also were widowed or divorced.

Before interpreting the findings in more detail, some methodological limitations of the study need to be considered. Women were followed only until their next pregnancy after the first induced abortion or until the end of the year 2008, so there might have been pregnancies with different outcomes after the study period ended and knowing the outcome of those pregnancies could affect the results. In particular, the fertility patterns of young women could not be identified perfectly because of the relatively short follow-up period.

The register-based data also set limitations to the study as the socio-demographic factors had to be limited to the variables registered by the Registry of Induced Abortions. For example, there was no information about ethnic background, number of siblings, or the socio-demographic features of spouse or parents, although these factors are likely to affect fertility patterns (Heikinheimo et al. 2009, 824; Kulu et al. 2007, 278-279; Murphy and Knudsen 2002; Régnier-Loilier 2006). Mainly data is of good quality, but some variables are not measured as precisely as the others (see Gissler et al. 1996), which can increase measurement error. Also, based on the assumptions of life course theory (see Elder et al. 2003) changes in socio-demographic characteristics over the life course may produce different outcomes than characteristics measured only in one point in time. The present data were limited to the women's characteristics at the time of the first abortion only.

Why were the studied socio-demographic factors important in predicting fertility after abortion? According to life course theory, age is a noteworthy variable in the studies of fertility behaviour. Not only the physical consequences of age (i.e. curvilinear relationship with fecundity from adolescence to adulthood), but also the age norms of society, are important, when women consider whether to have an abortion (see Elder et al. 2003; Elder 1985; Hayford \& Guzzo 2010). In Finland, having a child as a teenager or even at the first years after the age of 20 , is not considered appropriate, because of possible economic (and other) hardship caused by childbearing at a young age (Kelhä 2010). Performing induced abortions, by contrast, is widely accepted: 65 percent of all 
the Finns accept free abortion (Kontula 2008, 86) and in a study about Finnish women, only 5 percent were against abortion in all situations (Notkola 1993, 87-95). This might cause teenagers to have an induced abortion in the case of unintended pregnancy, as that is seen as a responsible thing to do in the situation, even if she had had induced abortion(s) before. Women in their twenties and thirties are already considered to be in the right stage at their lives to start a family (Knudsen et al. 2003), so repeat abortion, especially if her work situation is stable and the woman has a partner, may not be considered as an appropriate option.

From life history theory point of view it is easy to understand why parity was such a significant factor in predicting the fertility behaviour after the first induced abortion. According to Hrdy (1999), women tend to invest in their own well-being before they have children, because this guarantees the well-being of their children as well. Thus, mother's resources are important in determining whether or not to abort the unwanted pregnancy. Furthermore, this was in line with the micro-economic models of fertility, which suggest that the more people want to invest in their children, the more the limit the number of them (Becker 1991). Cultural factors may also have contributed to the abortion decisions of parous women. Lesthaeghe (2010) stresses that individualistic values have resulted in decreased fertility in Western countries.

The effect of parity on repeat abortion can also be explained with the findings of previous empirical studies. In a Swedish study about abortion motives, women in their thirties said that the main reason for induced abortion was that they did not want to have more children (Larsson et al. 2002). Assuming that in Finland the motivations to have an abortion are approximately the same as in Sweden, the effect of parity in repeat abortion can be explained based on the willingness to limit the number of children in a family at least in the case of the older women of the data. However, the reason of the unintended pregnancy in the first place remains unknown. According to Larsson et al. (2002) the main reason for that was the failure of contraception. Even though the respondents claimed to know how to use contraception methods, many of them were unaware why it had failed this time (ibid). A Finnish study by Vikat, Kosunen and Rimpelä (2002) showed an increased risk of induced abortion shortly after childbirth. Researchers suggested that the risk increases, because parents may believe that lactation is an effective way to prevent unwanted pregnancies, even though this is not always the case. Better postpartum contraceptive counselling could solve these problems. (Ibid). In a Russian study, women who received systematic counselling after an induced abortion were much less likely to abort again than those who did not receive any (Curtis et al. 2010). In the light of these previous studies as well as the results of this one, it seems that not only post-abortion counselling, but also counselling of parents of infants in Finland is extremely important. Many of the abortions performed for parous women could have been prevented, had they received essential information about contraception and therefore perfecting the counselling system is crucial. 
In a cohort study of Finnish women born in 1966, Pouta et al. (2005) discovered that 14 percent of the first pregnancies of the women were reported to have been either unwanted or mistimed, even though they were asked about the desirability of the pregnancy retrospectively (which normally results in a smaller proportion reported unwanted, because their attitude might have changed since the beginning of an initially unwanted pregnancy) (ibid, 197-9). It seems that although there are effective contraception methods available in Finland, unintended pregnancies still occur quite frequently. Wildsmith et al. (2010) and Hayford and Guzzo (2010) have suggested that the planning status of pregnancies is not only related to whether they were actually planned but also to the acceptability of the pregnancy in given social context and the stage of woman's life course.

Socio-economic status showed to be less important than expected. SES clearly affected the likelihood of childbirth for childless women (the higher the SES was the greater was the likelihood of childbirth and all groups were more likely to give birth after their first induced abortion than students and housewives), but otherwise the effects were small or non-existent. Repeat abortion was more likely for manual workers, unemployed persons and housewives than for other groups, but these differences were modest. However, these results are in line with a German study by Michaela Kreyenfeld (2010), which hypothesised that women in an insecure economic position are less likely to have children than those in secure jobs. Students, housewives and unemployed women postpone parenthood, because having children could affect their career negatively. This was especially the case for academic women. (Ibid).

The most interesting result considering marital status was the increased probability of divorced women to give birth. The interaction effect of parity with marital status suggested that this might be due to stepfamilies, because the effect was the strongest for divorced women who already had children. Spouses who already have children from previous relationships may wish to have children together as well. For these women, the reason for first induced abortion might have been related to their divorce at the time. When we studied the effect of the change in the relationship status, it was obvious that being in a relationship or starting one after the first induced abortion increased the likelihood of childbirth in comparison to induced abortion. Even though some scholars have suggested that marriage is no longer a condition for childbearing (Lesthaeghe, 2010), at least being in a relationship seems to be important, as in this study women preferred giving birth when they were living with their partner. Although being married is not a condition for childbearing, the preference of delivery in a relationship can be explained by cultural norms that consider it more appropriate to have children in a relationship than without one (Barber 2001). It also is possible that the resources and security provided by the partner (e.g. help with childcare, financial resources), also affected the decision to rather give birth when being in a relationship. 
Given the considerable differences in fertility rates between urban and rural areas (see Kulu et al. 2007), we expected the differences to exist in abortion behaviour as well. Supporting our hypothesis, population density had an effect on probability of delivery and abortion. The likelihood of delivery was higher and the likelihood of repeat abortion smaller in rural than urban areas, although, the effect was small especially in the case of abortions. Kulu, Vikat and Andersson (2007) propose that one reason that people living in rural areas have more children than people in cities is that cultural norms differ and religiosity is more effective in the countryside. All of the women in our study had performed at least one induced abortion, implying that they probably do not represent the average rural values considering family formation, as abortion has at least once been an option for them. This might resulted in a smaller effect of environment than expected. Furthermore, migration between areas of different level of urbanisation was not taken in account, which may have biased the estimates of rural vs. urban areas. However, Kulu et al. $(2007,278)$ showed that internal migration does not explain the fertility differences between urban and rural environments, as migrants tend to adopt the fertility behaviour dominant in their living environment (rather than families with many children moving to rural areas) .

In conclusion, socio-demographic determinants were found to predict women's fertility decisions after their first induced abortion. These socio-demographic patterns should be taken into account when developing post-abortion counselling, as women with different backgrounds have different needs. As there was a significant increase of repeat abortions in parous women, postpartum counselling concerning contraception methods should also be stressed.

\section{References}

Barber, Jennifer S. 2001. Ideational Influences on the Transition to Parenthood: Attitudes Toward Childbearing and Competing Alternatives. Social Psychology Quarterly 64 (2): 101-27.

Becker, Gary S. 1991. A Treatise on the Family. Enlarged edition. Cambridge: Harvard University Press.

Bongaarts, John and Robert G. Potter. 1983. Fertility, Biology and Behavior. An Analysis of the Proximate Determinants. New York: Academic Press.

Curtis, Carolyn, Douglas Huber and Tamarah Moss-Knight. 2010. Postabortion Family Planning: Addressing the Cycle of Repeat Unintended Pregnancy and Abortion. International Perspectives on Sexual and Reproductive Health 36 (1): 44-8.

Elder, Glen H. Jr. 1985. Perspectives on the Life Course. In: Life Course Dynamics. Trajectories and Transitions 1968-1980, edited by Glen H. Elder Jr., pp. 23-49, Ithaca and London: Cornell University Press.

Elder, Glen H. Jr., Monica Kirkpatrick Johnson and Robert Crosnoe. 2003. The Emergence and Development of Life Course Theory. In: Handbook of the Life Course, edited by Jeylan T. Mortimer and Michael J. Shanahan, pp. 3-19, New 
York: Kluwer Academic/Plenium publishers.

Gissler, Mika, Veli-Matti Ulander, Elina Hemminki and Anja Rasimus. 1996. Declining induced abortion rate in Finland: Data quality of the Finnish Abortion Register. International Journal of Epidemiology 25 (2): 376-80.

Hayford, Sarah R. and Karen Benjamin Guzzo: Age, relationship status, and the planning status of births. Demographic Research 23 (13): 365-98.

Heino, Anna, Mika Gissler and Anne Soimula. 2009. Induced Abortions and Sterilisations 2008. Official Statistics of Finland Statistical report 15/2009.

Heikinheimo, Oskari, Mika Gissler and Satu Suhonen. 2009. Can the outcome of the next pregnancy be predicted at the time of induced abortion? Human Reproduction 24 (4): 820-6.

Hrdy, Sarah Blaffer. 1999. Mother Nature. A History of Mothers, Infants and Natural Selection. New York: Pantheon Books.

Kelhä, Minna. 2010. Vääränikäisiä äitejä? Ikä ja äitiyden yhteiskunnalliset ehdot. [Mothers at the wrong age? Age and the social conditions of motherhood.] Nuorisotutkimus 28 (2): 70-75.

Knudsen, Lisbeth B., Mika Gissler, Soley S. Bender, Clas Hedberg, Ulla Ollendorff, Kaisa Sundström, Kristina Totlandsdal and Sigridur Vilhjalminsdottir. 2003. Induced abortion in the Nordic countries: special emphasis on young women. Acta Obstetricia et Gynecologica Scandinavica 82 (3): 257-68.

Kontula, Osmo. 2008. Halu ja intohimo. Tietoa suomalaisesta seksistä. [Desire and passion. Knowledge of Finnish sex.] Helsinki: Otava.

Kreyenfeld, Michaela. 2010. Uncertainties in Female Employment Careers and the Postponement of Parenthood in Germany. European Sociological Review 26 (3): 351-366.

Kulu, Hill, Andres Vikat and Gunnar Andersson. 2007. Settlement size and fertility in the Nordic countries. Population Studies 61 (3): 265-85.

Larsson, Margareta, Gunilla Aneblom, Viveca Odlind and Tarja Tyden. 2002. Reasons for pregnancy termination, contraceptive habits and contraceptive failure among Swedish women requesting an early pregnancy termination. Acta Obstetricia et Gynecologica Scandinavica 81 (1): 64-71.

Lesthaeghe, Ron J. 2010. The Unfolding Story of the Second Demographic Transition. Population and Development Review 36 (2): 211-51.

Murphy, M and Lisbeth B. Knudsen. 2002. The intergenerational transmission of fertility in contemporary Denmark: The effects of number of siblings (full and half), birth order, and whether male or female. Population Studies 56 (3): 235-48.

Niinimäki, Maarit, Anneli Pouta, Aini Bloigu Mika Gissler, Elina Hemminki, Satu Suhonen, and Oskari Heikinheimo. 2009. Frequency and Risk Factors for Repeat Abortions After Surgical Compared With Medical Termination of Pregnancy. Obstetrics \& Gynecology 113 (4): 845-52.

Notkola, Irma-Leena. 1993. Suomalaisten suhtautuminen aborttiin. [The abortion attitudes of Finns.] In: Raskauden keskeyttäminen - suomalaisia valintoja 1990-luvulla, edited by Matti Rimpelä and Maija Ritamo, pp. 87-102, Helsinki: Stakes. 
Pouta, Anneli, Marjo-Riitta Järvelin, Elina Hemminki, Ulla Sovio and Anna-Liisa Hartikainen. 2005. Mothers and daughters: intergenerational patterns of reproduction. European Journal of Public Health 15 (2): 195-99.

Régnier-Loilier, Arnaud. 2006. L'influence de la fratrie d'origine sur le nombre souhaité d'enfants à différents moments de la vie. L'exemple de la France. [Influence of Own Sibship Size on Number of Children Desired at Various Times of Life. The Case of France.] Population (French Edition) 61 (3): 193-223.

Santelli, John, Roger Rochat, Kendra Hatfield-Timajchy, Brenda Colley Gilbert, Kathryn Curtis, Rebecca Cabral, Jennifer S. Hirsch and Laura Schieve. 2003. The Measurement and Meaning of Unintended Pregnancy. Perspectives on Sexual and Reproductive Health 35 (2): 94-101.

Shanahan, Michael J., Scott M. Hofer and Lilly Shanahan. 2003. Biological Models of Behavior and the Life Course. In: Handbook of the Life Course, edited by Jeylan T. Mortimer and Michael J. Shanahan, pp. 597-622, New York: Kluwer Academic/ Plenium publishers.

Singer, Judith D. and John B. Willett. 2003. Applied Longitudinal Data Analysis. Modeling Change and Event Occurrence. New York: Oxford University Press.

Statistics Finland. 2010. Classification of Socio-economic Groups 1989. (http://www. stat.fi/meta/luokitukset/sosioekon_asema/001-1989/index_en.html, cited 8, Oct. 2010)

Trent, Katherine and Eve Powell-Griner. 1991. Differences in Race, Marital Status and Education Among Women Obtaining Abortions. Social Forces 69 (4): 1121-41.

Vikat, Andres, Elise Kosunen and Matti Rimpelä. 2002. Risk of Postpartum Induced Abortion in Finland: A Register-Based Study. Perspectives on Reproductive and Sexual Health 34 (2): 84-90.

Väisänen, Heini. 2010. Abortin jälkeiseen hedelmällisyyteen vaikuttavat tekijät Suomessa. [Determinants of fertility after abortion in Finland.] Unpublished master's thesis study. University of Helsinki: Department of Social Research.

Wildsmith, Elisabeth, Karen Benjamin Guzzo and Sarah R. Hayford. 2010. Repeat Unintended, Unwanted and Seriously Mistimed Childbearing in the United States. Perspectives on Sexual and Reproductive Health 42 (1), 14-22. 